\title{
ПОСТАНОВЛЕНИЕ КОНСТИТУЦИОННОГО СУДА РОССИЙСКОЙ ФЕДЕРАЦИИ ОТ 17.02.2015 № 2-П И ЗНАЧИМОСТЬ ЕГО ОПИСАТЕЛЬНОЙ ЧАСТИ ДЛЯ ТЕОРИИ И ПРАКТИКИ ПРОКУРОРСКОГО НАДЗОРА
}

Аннотация: Предметом исследования настоящей статьи явилось содержание описательной части постановления Конституцуионного Суда Российской Федерациии от 17.02.2015 № 2-П, в котором всесторонней оценке с позиции конституцуионности подверглись отдельнье положения статьей 6, 21 и 22 Федерального закона "О прокуратуре Российской Федерации", регламентирующче вопросы применения прокурорами полномочий в рамках истребования у поднадзорных органов статистической и иной информации, а также проведения проверок исполнения законов в соответствующих органах. В качестве методологии исследования автор избрал сопоставление правовой позиции Конституциионного Суда Российской Федерации по указанным вопросам со складывающейся правоприменительной практикой. Научная новизна проведенного исследования заключается в том, что автором впервые проведен детальный анализ правовой позиции Конституциионного Суда Российской Федерации по наиболее проблемным вопросам, встречающчимся в правоприменительной практике, высказано критическое мнение об объективности содержащихся в постановлении органа конституционного контроля тезисов, а также подчеркнуты наиболее важные для теории и практики прокурорского надзора подходы.

Ключевые слова: Законность, исполнение законов, Конституционный Суд, органы прокуратуры, полномочия прокурора, постановление, правовая позиция, проверка, прокурор, прокурорский надзор.

Abstract: The subject of this research is the content of the descriptive part of the ruling of the Constitutional Court of the Russian Federation from 02.17.2015 No. 2-P, in which certain positions of Articles 6, 21, and 22 of the Federal Law “On Prosecutor's Office the Russian Federation" are subjected to a rigorous assessment from the perspective of constitutionality. These Articles regulate the issues pertaining to prosecutors exercising their authority within the framework of obtaining statistical and other information from the supervised branches, as well as inspections to ensure adherence to the laws within the corresponding branches. The scientific novelty of the research consists in the fact that the author is first to conduct a detailed analysis of the legal position of the Constitutional Court of the Russian Federation on the most problematic issues that come up in law enforcement practice; the author expresses a critical opinion on the objectiveness of the theses contained in the ruling of the branch of constitutional control, and underlines the most important approaches for the theory and practice of prosecutors supervision.

Keywords: Legality, Upholding the law, Constitutional Court, Prosecutor's office, Prosecutor's authority, Court ruling, Legal position, Inspection, Prosecutor, Prosecutors supervision.

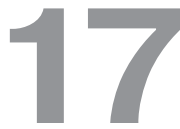

февраля 2015 г. за №2-П Конституционным Судом Российской Федерации (далее Конституционный Суд РФ) вынесено постановление «По делу о проверке конституционности положений пункта 1 статьи 6, пункта 2 статьи 21 и пункта 1 статьи 22 Федерального закона "О прокуратуре Российской Федерации" в связи в связи с жалобами межрегиональной ассоциации правозащитных общественных объединений "АГОРА", межрегиональной общественной организации "Правозащитный центр "Мемориал", международной общественной организации "Международное историко-просветительское, благотворительное и правозащитное общество "Мемориал", региональной общественной благо- творительной организации помощи беженцам и вынужденным переселенцам "Гражданское содействие", автономной некоммерческой организации правовых, информационных и экспертных услуг "Забайкальский правозащитный центр", регионального общественного фонда "Международный стандарт" в Республике Башкортостан и гражданки С.А. Ганнушкиной» (далее - Постановление № 2-П) [1], которое не могло остаться незамеченным в прокурорской среде, поскольку в своей описательной части и резолютивных выводах предопределило на обозримую перспективу единообразные подходы в толковании правоприменительного смысла статей 6, 21 и 22 Федерального закона от 17.01.1992 № 2202-1 «О прокуратуре Российской Федерации» (да- 
DOI: $10.7256 / 1811-9018.2015 .7 .15313$

При цитировании этой статьи сноска на доі обязательна

\section{Право и политика 7 (187) 2015}

лее - Закон о прокуратуре) [2]. При этом подчеркнем, что ограничение правосубъектного состава в рамках рассматриваемого судебного акта лишь некоммерческими организациями отнюдь не исключает, а, напротив, обязывает, прокуроров неукоснительно придерживаться в своей надзорной деятельности тех правовых позиций, которые нашли отражение в решении органа конституционного контроля.

Следует отметить, что статьи 21 и 22 Закона о прокуратуре и ранее являлись предметом изучения в Конституционном Суде РФ [3], однако, по нашему мнению, значимость содержащихся в Постановлении № 2-П выводов существенно превосходит ранее высказанные позиции, затрагивавшие узкие специфические вопросы. В этой связи правомерно говорить о стратегически важном его влиянии на последующую правоприменительную практику, внесение корректив в основы теории прокурорского надзора, а также на неизбежные законодательные новеллы, в рамках которых необходимо учесть, как нам представляется, и позиции Конституционного Суда РФ по указанным в сноске решениям, поскольку они не нашли до настоящего времени отражения в законотворческом процессе.

Принимая во внимание без преувеличения фундаментальный характер рассматриваемого судебного акта, полагаем необходимым в рамках настоящей статьи проанализировать ключевые положения его описательной части, поскольку они, помимо своей безусловной практической значимости, в немалой степени обусловливают введение в инструментарий прокурорской науки [4] ряда новых терминов, которые должны занять свое место в теории и пополнить профессиональный тезаурус.

Важное в плане научных дискуссий о роли и месте института прокуратуры в российском государстве значение имеют содержащиеся в п. 3 описательной части Постановления № 2-П подходы, а именно:

1) прокуратура Российской Федерации обозначена Конституционным Судом РФ как государственновластный институт, понимание роли и предназначения которого в правовой системе России и ее правовых традициях сложилось исторически. Это, безусловно, не точка в дискуссиях о том, относится ли прокуратура к органам государственной власти [5]. Речь идет о возможности применения прокурорами властных полномочий в рамках выполнения поставленных перед ними задач [6];

2) по смыслу положений Конституции России и основанных на них правовых позиций Конституционного Суда РФ, осуществляемая прокуратурой РФ функция надзора за исполнением законов является самостоятельной (обособленной) формой реализации контрольной функции государства, в рамках которой обеспечивается - путем своевременного и оперативного реагирования органов прокуратуры на ставшие известными факты нарушения субъектами права законов различной отраслевой принадлежности - неукоснительное соблюдение Конституции России и законов, действующих на территории Российской Федерации, в том числе теми государственными органами, на которые возложены функичи спеціиального (ведомственного) государственного контроля (надзора). Здесь мы оговоримся, что с точки зрения раздела III Закона о прокуратуре и основ теории прокурорской деятельности в качестве функции выступает все-таки прокурорский надзор, а надзор за исполнением законов является ее составной частью, именуемой отраслью;

3) принципиальное требование п. 2 ст. 21 Закона о прокуратуре, согласно которому при осуществлении надзора за исполнением законов органы прокуратуры не подменяют иные государственные органы, подчеркивает именно вневедомственный и межотраслевой характер прокурорского надзора как института, предназначенного для универсальной, постоянной и эффективной защиты конституционно значимых ценностей;

4) во взаимоотношениях с другими государственными органами, осуществляющими функции государственного контроля (надзора), прокуратура России занимает координирующее положение, что обусловливается наличием как специального правового регулирования порядка реализации ею надзорных функций [7], так и особого организационно-кадрового механизма, призванного обеспечивать реализацию функции надзора за исполнением законов [8] в системе органов прокуратуры лицами, имеющими высокую правовую квалификацию, и не требует детальной регламентации порядка реализации ими надзорных функций, более необходимой в отношении других видов государственного контроля (надзора).

Констатация того, что прокуратура России занимает координирующее положение среди органов контроля (надзора), требует дополнительных пояснений, тем более, что в пп. 5.4 описательной части Постановления № 2-П более конкретно говорится о координирующей роли прокуратуры Российской Федерации в сфере государственного контроля (надзора), которая не ставится под сомнение фактом привлечения прокурорами в рамках проведения надзорных проверок в качестве специалистов представителей других органов. Здесь следует отметить, что речь ни в коем случае не идет 
о традиционно понимаемой и закрепленной в ст. 1 и ст. 8 Закона о прокуратуре функции координации деятельности правоохранительных органов по борьбе с преступностью, которая приобретает несколько расширенные, хотя и в узкой сфере правоприменения, очертания в ч. 6 ст. 6 Федерального закона от 25.12.2008 № 273-Ф3 «О противодействии коррупции» [9], определяющей, что «Генеральный прокурор Российской Федерации и подчиненные ему прокуроры координируют деятельность... правоохранительных органов по борьбе с коррупиией». В равной мере не это имеют ввиду и при наделении прокуроров в научной литературе официально не существующим статусом «координатора координаторов» [10].

Вместе с тем, полагаем, что в немалой мере поддерживает рассматриваемый тезис Конституционного Суда РФ вступившая в силу с 1 января 2014 г. часть 2.2 ст. 77 Федерального закона от 06.10.2003 № 131-Ф3 «Об общих принципах организации местного самоуправления в Российской Федерации» [11], согласно которой органы прокуратуры осуществляют «координацию деятельности органов государственного контроля (надзора) по планированию и проведению проверок в отношении органов местного самоуправления и должностных лиц местного самоуправления».

Определенной научной предпосылкой рассматриваемого вывода может служить и совместная работа Д.Х. Талипова и Д.Ю. Болдырева [12], которые отмечают, что «для эффективного функционирования системы контроля за исполнением законодательства помимо вертикального способа координации деятельности звеньев государственного аппарата необходима и некая независимая система, разрешающая проблемы межведомственного взаимодействия на всех уровнях, начиная с федерального и заканчивая местным», подчеркивая, что «координирующая роль прокуратуры в настоящее время проявляется в создании и функционировании на различных уровнях различных межведомственных рабочих групп, проведении межведомственных совещаний, направленных на решение конкретных практических проблем»;

5) федеральный законодатель, действуя в пределах достаточно широкой дискреции и используя сочетание общих и дифференцированных подходов к правовому регулированию осуществления государственными органами контрольно-надзорных функций и полномочий, вправе устанавливать в соответствии с требованиями, вытекающими из Конституции России, определенные особенности организации и осуществления прокурорского надзора за исполнением законов, в том числе в сфере деятельности некоммерческих организаций (объединений). В данном случае подчеркивается, что надзорная деятельность прокуроров не должна в обязательном порядке подчиняться требованиям Федерального закона от 26.12.2008 № 294-Ф3 «О защите прав юридических лиц и индивидуальных предпринимателей при осуществлении государственного контроля (надзора) и муниципального контроля» (далее - Закон № 294-Ф3) [13]. Отметим, что в п. 3 ч. 3 ст. 1 названного законодательного акта прямо закреплено, что его положения, устанавливающие порядок организации и проведения проверок, не применяются при осуществлении прокурорского надзора, равно как и при проведении контрольно-надзорных мероприятий рядом других, преимущественно относящихся к исполнительной власти органов.

Вместе с тем необходимо подчеркнуть, что вопрос о необходимости более жесткой регламентации процедур осуществления надзорной проверки является актуальным. В одной из своих работ мы указывали на то, что «представляется необходимым закрепить в Законе о прокуратуре алгоритм проверки» [14], а в другой статье предложили конкретную формулировку [15].

Пункт 4 описательной части Постановления № 2-П также содержит отдельные положения, представляющие интерес для прокурорской науки, наиболее существенные из них заключаются в следующем:

1) возложение на Министерство юстиции Российской Федерации (далее - Минюст России) федерального государственного надзора за осуществлением некоммерческими организациями своей деятельности в соответствии с их конституционным предназначением не nрепятствует отнесению этой деятельности, как имеющей важное общественное и публично-правовое значение, одновременно к объекту прокурорского $\boldsymbol{\mu a д з о р а , ~ в ~ р а м к а х ~ к о т о р о г о ~ о б е с п е ч и в а ю т с я ~ н е ~ т о л ь к о ~}$ своевременное и адекватное реагирование, в том числе в экстраординарном (внеплановом) порядке, на ставшие известными факты нарушения некоммерческими организациями законов, но и надлежащее, законное и обоснованное осуществление федерального государственного надзора со стороны Минюста России.

Приведенная позиция подчеркивает обозначенный в п. 3 Постановления № 2-П тезис об особом предназначении прокурорского надзора в структуре органов, осуществляющих контрольную функцию государства, а равно о двойственной природе надзорной деятельности прокурора, которая выражается, в том числе в проверке законности деятельности других контрольнонадзорных органов; 
DOI: $10.7256 / 1811-9018.2015 .7 .15313$

При цитировании этой статьи сноска на доі обязательна

\section{Право и политика 7 (187) • 2015}

2) объективно присущее федеральному государственному надзору административное усмотрение проверяющих органов, не исключающее возможность использования имеющегося в их распоряжении правового инструментария вопреки его публичному предназначению, в том числе в понимаемых определенным образом ведомственных интересах, предполагает необходимость обеспечения в рамках правового регулирования федерального государственного надзора надлежащих гарантий прав гражљан и их объединений, с тем чтобы без ущерба для эффективности проводимых проверочных мероприятий минимизировать их возможное негативное воздействие, - безотносительно к тому, потребуют ли результаты проверки применения мер государственного принуждения, ограничивающих права и свободы человека и гражданина.

Отмеченный тезис весьма важен, поскольку подчеркивает необходимость четкого регулирования процедур применения прокурорами властных полномочий. К сожалению, положения ст. 22 Закона о прокуратуре, раскрывающей круг надзорных полномочий прокурора, отличаются чрезмерной лаконичностью, что не может не приводить на практике к случаям «творческого» подхода к их реализации. И это обстоятельство вынуждает Генеральную прокуратуру РФ периодически в своих информационных письмах обращать внимание нижестоящих прокуроров на необходимость более взвешенного подхода к применению полномочий. В частности, хотя Закон о прокуратуре и не содержит ограничений на направление запросов в поднадзорные органы, предписано подписывать их исключительно прокурорам, возглавляющим органы прокуратуры, и их заместителям. В свое время Генеральным прокурором РФ даже было издано указание от 08.08.2011 № 236/7 «Об исключении из практики прокурорского надзора фактов необоснованного вмешательства в деятельность органов государственной власти, органов местного самоуправления, иных органов и организаций» [16], на смену которому пришел ныне действующий приказ от 21.06.2013 № 252 «О совершенствовании прокурорского надзора за исполнением федерального законодательства органами государственной власти, местного самоуправления, иными органами и организациями» [17];

3) требования к проверяемому субъекту при проведении проверочных мероприятий должны оцениваться с точки зрения их необходимости и пропорциональности, недопустимости вмешательства проверяющего органа в оперативную деятельность проверяемого, в том числе с учетом результатов проверок, проводившихся ранее как в рамках специального (ведомственного) государственного контроля (надзора), так и в порядке прокурорского надзора.

Фактически от этого предостерегают прокуроров пп. 8.4 и 8.6 приказа Генерального прокурора РФ от 07.12.2007 № 195 «Об организации прокурорского надзора за исполнением законов, соблюдением прав и свобод человека и гражданина» [18], требующие «при осуществлении прокурорского надзора не допускать необоснованного вмешательства в экономическую деятельность предприятий и организаций» и «не допускать использований полномочий прокуроров для создания препятствий правомерной предпринимательской деятельности участников экономических отношений».

В пункте 5 Постановления № 2-П нашли отражение следующие значимые положения:

1) особенности предмета Закона о прокуратуре, вытекающие из ст. 129 Конституции России, не предопределяют безусловную необходимость сосредоточения только в нем всего массива норм, касающихся порядка общенадзорной деятельности прокуратуры и связанных с осуществлением прав, обязанностей и гарантий проверяемых субъектов.

Таким образом, Конституционный Суд РФ подчеркнул, что полномочия прокурора, причем не только процессуальные, могут закрепляться и в других законодательных актах, а это, если продолжать высказанную позицию, может предполагать и специфику в предмете прокурорского надзора в регулируемой тем или иным законодательным актом сфере. Например, согласно ч. 1 ст. 77 упомянутого выше Закона № 131-Ф3 органы прокуратуры осуществляют надзор за исполнением органами местного самоуправления и их должностными лицами не только законов, но и уставов муниципальных образований и муниципальных правовых актов;

2) наряду с осуществлением прокурорского надзора за исполнением законов в связи с конкретными обращениями (так называемые инцидентные основания), не исключается возможность проведения прокурорских проверок, в том числе в отношении некоммерческих организаций, в инициативном порядке, основания и поводы для которых тем не менее не могут определяться произвольно, - они должны быть связаны с конкретными сведениями, указывающими на наличие в деятельности некоммерческой организации и ее должностных лиц признаков нарушений законов.

Следует отметить что термин «инцидентное основание» до настоящего времени широко не применялся в прокурорской науке, поэтому он, скорее всего, пополнит профессиональный лексикон. Что касается противопоставления ему проверок, проводимых прокурором 
в «инициативном порядке», то нам с учетом положений п. 2 ст. 21 Закона о прокуратуре, закрепляющих основания для прокурорской проверки, видится не вполне корректный подход, в связи с чем такая двусмысленная характеристика применяться не должна;

3) основания прокурорской проверки обусловливают предмет и пределы ее проведения, в связи с чем реализация прокурором предоставленных ему в рамках функции надзора полномочий вне оснований конкретной проверки исполнения законов некоммерческой организацией и ее должностными лицами, по общему правилу, недопустима, за исключением случаев, когда в ходе ее проведения выявляются признаки иных нарушений законов, оценка которых также не может быть дана вне мероприятий собственно прокурорского надзора.

Важность этого тезиса заключается в том, что, с одной стороны, прокурор в ходе проверки связан необходимостью проверки того круга доводов, которые содержатся в источнике поступившей в прокуратуру информации, однако, с другой стороны, если в процессе осуществления проверочных мероприятий вскрываются не известные до этого новые факты, свидетельствующие о нарушениях законов на поднадзорном объекте, прокурор не вправе оставить их без внимания, поскольку это противоречило бы целевым установкам п. 2 ст. 1 Закона о прокуратуре, предопределяющим смысл и содержание прокурорской деятельности;

4) поскольку осуществление прокурором надзорной функции непосредственно затрагивает права и свободы проверяемых лиц, о начале проведения прокурорской проверки и о расширении в связи с выявленными признаками иных нарушений законов оснований ее проведения должно выноситься самостоятельное мотивированное решение, подлежащее доведению до сведения проверяемой некоммерческой организации, по крайней мере, в момент начала проверки.

Это положение является весьма актуальным, поскольку в определенных случаях именно соответствующее решение (требование, уведомление) может свидетельствовать о факте нарушения законных требований прокурора со стороны должностных и иных лиц поднадзорных объектов. И не случайно в пособии «Образцы документов прокурорской практики» [19] нами предложен вариант «Уведомления о проведении проверки»;

5) в подпункте 5.3 Постановления № 2-П подчеркивается, что требование прокурора о представлении руководителями и другими должностными лицами поднадзорного объекта относящихся к существу прокурор- ской проверки конкретных документов и материалов следует считать правомерным, если такие документы и материалы не могут быть получены у других государственных органов или из открытых источников и не передавались ранее в рамках данной прокурорской проверки, притом что органы прокуратуры не вправе запрашивать документы, которые организация не обязана иметь в соответствии с законодательством, в том числе требовать формирования документов, не имеющихся на момент предъявления такого требования.

Это очень важное положение, которое в общем созвучно ряду требований по указанному вопросу, сформулированных в организационно-распорядительных документах Генерального прокурора РФ, однако значимость его заключается в том, что оно имеет не внутриведомственный характер, когда прокурор на вопрос поднадзорного субъекта может ответить, и такое на практике имеет место, что требования приказов руководителя прокурорской системы касаются только прокуроров и никого более, а в полном смысле этого слова надведомственное усмотрение, фактически приравненное к норме закона;

6) Конституционным Судом РФ, с одной стороны, признано неправомерным проведение повторной проверки в отношении одного и того же объекта в связи с одними и теми же фактами, что представляется разумным. То есть прокурор не вправе произвольно неоднократно проверять один и тот же объект, какими бы мотивами он не руководствовался. Вопрос в этом случае сводится к одной единственной попытке, которую необходимо исполнить как можно эффективнее.

С другой стороны, Суд признал обоснованным проведение в разумный срок после первоначальной прокурорской проверки, по итогам которой в деятельности поднадзорного объекта были выявлены нарушения законов, проверки их устранения, поскольку при ином подходе, ставилась бы под сомнение эффективность прокурорского надзора как такового, а также исключалась бы возможность контроля за деятельностью органа прокуратуры, проводившего первоначальную проверку, вышестоящим органом прокуратуры.

Указанный тезис очень важен как в теоретическом, так и в практическом плане, поскольку допускает возможное проведение проверки в порядке контроля со стороны вышестоящей прокуратуры, что в принципе находило отражение в научных работах различных авторов, но с практической точки зрения вызывало обоснованные, на наш взгляд, сомнения в легитимности такого подхода. Ну и конечно же отмеченным походом признается правомерной возможность само- 
DOI: $10.7256 / 1811-9018.2015 .7 .15313$

При цитировании этой статьи сноска на доі обязательна

\section{Право и политика 7 (187) • 2015}

го проводившего проверку прокурора проконтролировать состояние исполнения изложенных им в акте прокурорского реагирования требований, что широко практикуется;

7) важное значение в условиях недостаточной определенности п. 1 ст. 22 Закона о прокуратуре имеет тезис о допустимости привлечения прокурорами для проведения своих проверок представителей иных государственных органов (полагаем, что в равной мере это относится к и муниципальным служащим), которым придается статус специалистов, компетентных в решении вопросов, которые возникли или могут возникнуть в ходе прокурорской проверки. При этом участие в проведении прокурорской проверки представителей (сотрудников) других государственных органов не предполагает самостоятельного осуществления ими проверочных действий в интересах соответствуюших государственных органов.

Специалисты из других органов достаточно часто привлекаются для проведения прокурорских проверок и нередко они выходят за рамки осуществления исключительно вспомогательной (экспертно-аналитической) деятельности, по существу выполняя, пусть и в рамках прокурорской проверки, мероприятия проверочного характера. Приведенная позиция Конституционного Суда РФ явно должна способствовать корректировке правоприменительной практики.

В то же время Суд высказал мнение, что указанное обстоятельство не исключает установления правового регулирования, в рамках которого возможно осуществление органами прокуратуры и иными органами государственного контроля (надзора), согласованных (совместных) контрольно-надзорных мероприятий в отношении одних и тех же объектов с соблюдением предъявляемых к соответствующим государственным органам специального (ведомственного) государственного контроля (надзора) требований.

В теории прокурорского надзора при классификации прокурорских проверок называются и совместные, проводимые с другими структурами. Однако буквальное понимание приведенного в Постановлении № 2-П тезиса приводит к выводу о том, что без включения соответствующей нормы в Закон о прокуратуре или иной федеральный закон (например, Закон № 294-ФЗ) подобное сотрудничество, которое широко распространено в настоящее время, в принципе недопустимо;

8) Конституционным Судом РФ высказана позиция, что отсутствие в Законе о прокуратуре прямого указания на необходимость оформления в виде отдельного акта результатов прокурорской проверки, не выявившей нарушений законов, не освобождает прокурора от необходимости принятия по ее итогам соответствующего решения с доведением его до сведения проверяемого объекта, поскольку без принятия такого решения прокурорская проверка в формально-юридическом смысле не могла бы считаться завершенной, что позволяло бы прокурору - вопреки целям осуществления прокурорского надзора - использовать предоставленные ему властные полномочия в отношении поднадзорного объекта неопределенно длительный срок.

Этот тезис нельзя рассматривать однозначно. С одной стороны, в случае выявления нарушения прокурор ограничивается актами прокурорского реагирования, которые адресует уполномоченным на их рассмотрение лицам, но при этом Суд не считает необходимым для прокурора составлять по итогам проверки итоговый документ. С другой стороны, какую информацию должен вносить прокурор в справку или акт по итогам нерезультативной проверки, да еще и знакомить с этим документом уполномоченных на то лиц - это вопрос, требующий законодательного закрепления;

9) отсутствие в Законе о прокуратуре специальных норм, регулирующих права некоммерческих организаций при проведении прокурорских проверок исполнения ими законов, не ставит под сомнение необходимость обеспечения тем поднадзорным объектам, чьи права и законные интересы затронуты проведением мероприятий прокурорского надзора, гарантий своевременной и эффективной судебной защиты их прав.

В Постановлении № 2-П подчеркнуто, что могут быть оспорены запрос должностных лиц органов прокуратуры о представлении необходимых сведений и документов, а также иные решения, действия (бездействие) указанных должностных лиц. При этом обязанность доказывания законности своих требований и решений лежит на прокуроре.

В последнее время проблемы обжалования решений и действий (бездействия) прокуроров вызывают определенный научный интерес [20] и в этом плане позиция Конституционного Суда РФ, как представляется, обусловит активизацию обращений в суд поднадзорных органов и лиц на предмет правомерности применения прокурорами своих полномочий;

10) подчеркнуто, что наличие у прокурора возможности произвольно устанавливать временные границы исполнения своих требований и тем самым по собственному усмотрению определять в этой части порядок реализации закрепленных за ним властных полномочий создает условия для нарушения консти- 
DOI: $10.7256 / 1811-9018.2015 .7 .15313$

При цитировании этой статьи сноска на dоі обязательна

Закон и правопорядок

myияионных прав некоммерческих организаций и причастных к их деятельности лиц вследствие возложения на них объективно невыполнимых в установленный срок требований прокурора, законность которых - при отсутствии нормативно формализованных критериев определения этого срока - не может быть подвергнута эффективному судебному контролю.

Суд отметил, что неурегулированность в Законе о прокуратуре вопроса об общей (предельной) продолжительности проверок исполнения законов, хотя они и имеют главным образом документарный (камеральный) характер, позволяет определять ее в каждом конкретном случае по произвольному усмотрению прокурора на основе его собственной субъективной оценки, исходя из результативности проверочных мероприятий.
Таким образом, подводя итог проведенному анализу положений описательной части Постановления № 2-П, отметим, что в них содержится ряд значимых для прокурорской науки догматических подходов, которые должны снизить накал дискуссий по затронутым вопросам. В то же время очевидна, прежде всего, практическая значимость высказанных Конституционным Судом РФ позиций, фактически легализующих отдельные сложившиеся в правоприменительной практике формы надзорной деятельности, обусловленные чрезмерной лаконичностью формулировок рассмотренных статей Закона о прокуратуре. Анализ резолютивной части Постановления № 2-П будет проведен в самостоятельной статье.

\section{Библиография:}

1. СЗ РФ. - 2015. - № 9. - Ст. 1389.

2. СЗ РФ. - 1995. - № 47. - Ст. 4472 (с послед. изменениями).

3. Постановления Конституционного Суда РФ от 11.04.2000 № 6-П «По делу о проверке конституционности отдельных положений пункта 2 статьи 1, пункта 1 статьи 21 и пункта 3 статьи 22 Федерального закона «О прокуратуре Российской Федерации» в связи с запросом Судебной коллегии по гражданским делам Верховного Суда Российской Федерации» (СЗ РФ. - 2000. - № 16. - Ст. 1774) и от 18.07.2003 № 13-П «По делу о проверке конституционности положений статей 115 и 231 ГПК РСФСР, статей 26, 251 и 253 ГПК Российской Федерации, статей 1,21 и 22 Федерального закона «О прокуратуре Российской Федерации» в связи с запросами Государственного Собрания Курултая Республики Башкортостан, Государственного Совета Республики Татарстан и Верховного Суда Республики Татарстан» (С3 РФ. - 2003. - № 30. - Ст. 3101).

4. О значении этого понятия см.: Винокуров А.Ю. Прокурорская наука: состояние и перспективы развития // Журнал российского права. - 2014. - № 9. - С. 125-130.

5. Бессарабов В.Г., Жмакин А.С. Место прокуратуры в политической системе // Законность. - 2009. - № 11; Велиев И.В. Место прокуратуры в системе органов государственной власти Российской Федерации // Современное право. - 2005. - № 10 и др.

6. Байкин И.М. К вопросу о государственно-властных полномочиях прокуратуры // Государственная власть и местное самоуправление. - 2011. - № 4.

7. Подчеркнем, что с точки зрения прокурорской науки надзорная функция одна и в Законе о прокуратуре она обозначена как прокурорский надзор.

8. Такой функции у прокуратуры нет, поскольку надзор за исполнением законов является отраслью (составной частью) функции прокурорского надзора.

9. СЗ РФ. - 2008. - № 51 (ч. 1). - Ст. 6228 (с послед. изменениями).

10. Гулягин А.Ю. Прокуратура в системе правоохранительных органов административной юрисдикции: монография. - М.: Юрист, 2012 // СПС «КонсультантПлюс».

11. СЗ РФ. - 2003. - № 40. - Ст. 3822 (с послед. изменениями).

12. Талипов Д.Х., Болдырев Д.Ю. Надзор за исполнением законов: подмена функций контролирующих органов или координация их деятельности // Законность. - 2012. - № 4. - С. 28-33.

13. СЗ РФ. - 2008. - № 52 (ч. 1). - Ст. 6249 (с послед. изменениями).

14. Винокуров А.Ю. Полномочия прокурора по надзору за исполнением законов // Законность. - 2006. - № 8 .

15. Винокуров А.Ю. К вопросу о совершенствовании правового регулирования надзорной и иной деятельности прокуроров // Актуальные вопросы российского права: сб. науч. статей. - М.: МосГУ, 2010. - Вып. 17. - С. 16.

16. Законность. - 2011. - № 12 .

17. СПС «КонсультантПлюс».

18. Законность. - 2008. - № 3 (с послед. изменениями).

19. Образцы документов прокурорской практики: практ. пособие /под общ. ред. А.Э. Буксмана и О.С. Капинус. - М.: Юрайт, 2014. - C. 35-36.

20. Бондаренко В.А., Ершова В.А. Законность оспаривания представления прокурора // Законность. - 2014. - № 6. - С. 9-12; Глухов Е.А. О возможности оспаривания актов прокурорского реагирования // Право в Вооруженных Силах. - 2014. - № 3. - С. 99-109 и др. 
DOI: $10.7256 / 1811-9018.2015 .7 .15313$

При цитировании этой статьи сноска на доі обязательна

\section{Право и политика 7 (187) • 2015}

\section{References (transliterated):}

1. Bessarabov V.G., Zhmakin A.S. Mesto prokuratury v politicheskoi sisteme // Za-konnost'. - 2009. - № 11; Veliev I.V. Mesto prokuratury v sisteme organov gosudarstvennoi vlasti Rossiiskoi Federatsii // Sovremennoe pravo. - 2005. - № 10 i dr.

2. Baikin I.M. K voprosu o gosudarstvenno-vlastnykh polnomochiyakh prokuratury // Gosudarstvennaya vlast' i mestnoe samoupravlenie. - 2011. - № 4 .

3. Gulyagin A.Yu. Prokuratura v sisteme pravookhranitel'nykh organov administrativnoi yurisdiktsii: monografiya. - M.: Yurist, 2012 // SPS «Konsul'tantPlyus».

4. Talipov D.Kh., Boldyrev D.Yu. Nadzor za ispolneniem zakonov: podmena funktsii kontroliruyushchikh organov ili koordinatsiya ikh deyatel'nosti // Zakonnost'. - 2012. - № 4. - S. 28-33.

5. Vinokurov A.Yu. Polnomochiya prokurora po nadzoru za ispolneniem zakonov // Zakonnost'. - 2006. - № 8 .

6. Vinokurov A.Yu. K voprosu o sovershenstvovanii pravovogo regulirovaniya nadzornoi i inoi deyatel'nosti prokurorov // Aktual'nye voprosy rossiiskogo prava: sb. nauch. statei. - M.: MosGU, 2010. - Vyp. 17. - S. 16.

7. Bondarenko V.A., Ershova V.A. Zakonnost' osparivaniya predstavleniya prokurora // Zakonnost'. - 2014. - № 6. - S. 9-12; Glukhov E.A. O vozmozhnosti osparivaniya aktov prokurorskogo reagirovaniya // Pravo v Vooruzhennykh Silakh. - 2014. № 3. - S. 99-109 i dr. 